\title{
Breast Involvement in Anti-Neutrophil Cytoplasmic Antibodies Positive Granulomatosis With Polyangiitis in a 64-Year-Old Female Patient
}

\author{
Monika RYBA, Andrzej KONIECZNY, Zbigniew HRUBY
}

Department of Nephrology, Voivodship Specialty Hospital, Center For Research and Development, Wroclaw, Poland

\begin{abstract}
In this article, we present a case of a female patient suffering from granulomatosis and polyangiitis with active glomerular disease, who developed exacerbation of pulmonary vasculitis and palpable tumors of right breast. A possibility of neoplastic disease was excluded by histopathological examination of percutaneous biopsy specimen, revealing granulomatous inflammatory infiltrate, without any features of neoplasia. Moreover, both pulmonary and breast lesions subsided following intensification of immunosuppressive/antiinflammatory treatment.

Keywords: Anti-neutrophil cytoplasmic antibodies; breast; glomerulonephritis; granulomatosis with polyangiitis.
\end{abstract}

Granulomatosis with polyangiitis is an autoimmune disease, characterized by involvement of small vessels and presence of anti-cytoplasmic antibodies (ANCA). From the 2011, according to recommendations of the American College of Rheumatology and the American Society of Nephrology, the term granulomatosis with polyangiitis has been adopted. A wide range of manifestations characterizes the disease. It affects skin and subcutaneous tissue, upper and lower respiratory tract, heart, kidneys, as well as the nervous and musculoskeletal systems.

\section{CASE REPORT}

A 64-year-old female patient, diagnosed with granulomatosis and polyangiitis, remaining under care of the Department of Nephrology, was admitted for the sixth pulse of cyclophosphamide in a protocol inducing remission of glomerulonephritis. From the diagnosis, the patient was treated with intravenous pulses of cyclophosphamide, $750 \mathrm{mg}$ each, at fourweek intervals, with total dose of $3,750 \mathrm{mg}$. Besides, from the time of diagnosis, pulse methylprednisolone (500 mg over three days), with continuation by oral prednisone $1 \mathrm{mg} / \mathrm{kg}$, tapered to $15 \mathrm{mg}$ every other day, was given. A written informed consent was obtained from the patient.

At initial admission to the hospital, the patient complained of weakness, cough, and hemoptysis. The chest X-ray demonstrated infiltrations of both upper lung fields. In addition, anemia, sub-nephrotic proteinuria and elevation of serum creatinine level to $1.5 \mathrm{mg} / \mathrm{dL}$ were demonstrated. Moreover, the presence of anti-neutrophil cytoplasmic antibodies in serum was disclosed [qualitative enzyme-linked immunosorbent assay]. The histopathologic image of percutaneous renal needle biopsy was consistent with the diagnosis of extracapillary glomerulonephritis due to systemic vasculitis. 
After implementation of immunosuppressive therapy described above, normalization of serum creatinine, regression of proteinuria, and above all, improvement of overall clinical condition were observed. The control chest X-ray, few weeks after diagnosis, showed no changes in the lung fields.

During each subsequent monthly hospitalizations, the patient remained in good general condition, the proteinuria and creatinine serum levels were within normal range. At one of the follow-up visits, nearly one month after the fifth pulse of cyclophosphamide, the patient reported thickening of the right breast, dry cough, and weakness. Chest X-ray demonstrated infiltrative lesion in the upper left lung field (Figure 1). A mild anemia was found, while breast ultrasound confirmed presence of knobby changes in the right breast. Accordingly, the administration of the next cyclophosphamide pulse was postponed and the patient was referred for oncologic consultation. Within the oncology clinic, a needle biopsy of the breast lesion was performed, revealing no neoplastic cells and the histopathological image corresponding to infiltration in the course of granulomatosis with polyangiitis gathering mainly around small size blood vessels (Figure 2). On the basis of infiltrative changes in the lungs, the result of breast biopsy, and presence of anti-neutrophil cytoplasmic antibodies, the recurrence of the

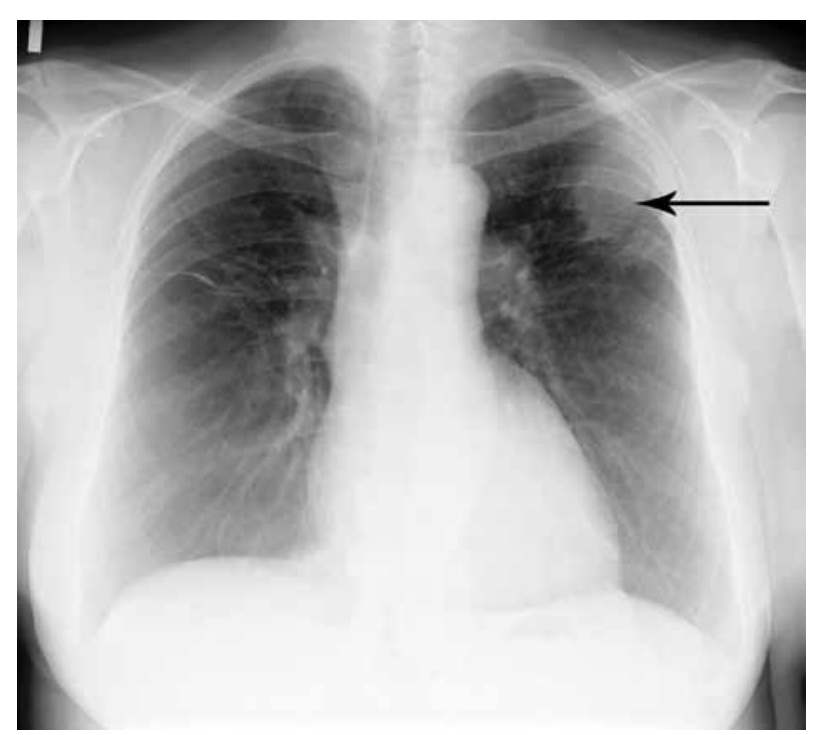

Figure 1. Chest X-ray demonstrating infiltrate in upper left lateral field of left lung. underlying disease was diagnosed. Accordingly, the prednisone dose was increased to $1 \mathrm{mg} / \mathrm{kg}$ with subsequent tapering to $15 \mathrm{mg} / \mathrm{day}$. Thus a gradual decrease in C-reactive protein levels with improvement of the patient's condition was observed. After a few days, a pulse of intravenous cyclophosphamide (1000 mg) was administered. Following intensification of immunosuppressive therapy, patient's condition improved, and normalization of serum $\mathrm{C}$-reactive protein was noted. Following five weeks, a control chest X-ray demonstrated no lung infiltrations. Since then, two pulses of cyclophosphamide (1000 mg each, four weeks apart) were given and the treatment with azathioprine, $100 \mathrm{mg}$ per day, has been started. Currently, the patient remains in complete remission.

\section{DISCUSSION}

Infiltration of the breast in course of granulomatosis with polyangiitis is rare. The most frequently affected organs are the upper respiratory tract, lungs, and kidney (89\%, 67\%, and 48\%, respectively), while the skin, salivary glands, breast, and genital involvements occur in less than $5 \%$ of cases. ${ }^{1-3}$ Not more than a few dozen of such cases have been described to date. Allende and Booth, ${ }^{4}$ in a report published in 2009 , described only 27 of these patients.

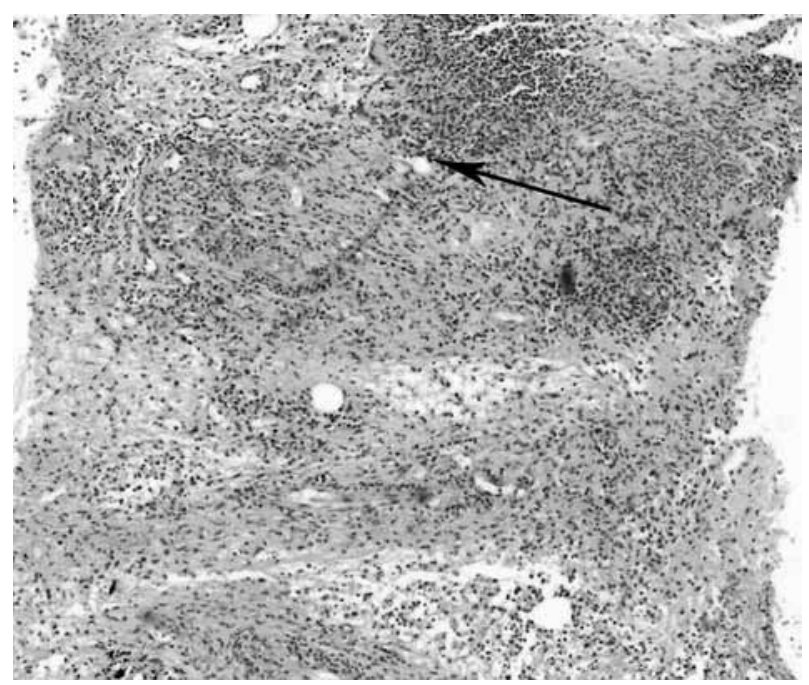

Figure 2. Breast biopsy. Mixed inflammatory infiltrate of lymphocytes and neutrophils involving mainly small vessels $(\mathrm{H}-\mathrm{E} \times 400)$. 
Symptoms of breast involvement in course of the disease rarely occur at the time of diagnosis, they usually appear later on, as in our case. There are two basic manifestations of granulomatosis with polyangiitis within the breast: solid tumor changes that may suggest a neoplastic disease, ${ }^{5}$ or abscesses and ulcerations, particularly of recurrent nature. ${ }^{6}$ The manifestation of granulomatosis with polyangiitis limited to mammary gland is rare. The differential diagnosis should include sarcoidosis, fungal infections, tuberculosis, and malignancies. The ultimate diagnosis depends on histopathologic examination. Characteristic changes include necrotizing granulomas and inflammatory cell infiltration around blood vessels.

The differential diagnosis of granulomatous mastitis includes breast cancer, infectious process (bacterial, fungal, or parasitic abscess), autoimmune disease (Wegener's vasculitis, giant cell arteritis), duct ectasia, other rare causes linked with systemic disease (diabetes mellitus, sarcoidosis), and idiopathic granulomatous mastitis. ${ }^{7}$ The idiopathic granulomatous mastitis affects females of childbearing age, typically few years postpartum, with history of breastfeeding and presents as painful lump, often with inflammation of the overlying skin, suspected of autoimmune or bacterial etiology (Corynebacterium). ${ }^{8}$ The characteristics of patient's history and clinical presentation in entities cited above are clearly distinct from the description of our case. Nevertheless, it is impossible to exclude any of the above diagnoses without histopathological examination of biopsy specimen.

Quickly established diagnosis with implementation of appropriate treatment inducing remission allowed to avoid unnecessary surgery in this case of systemic vasculitis. Therefore, it is always advisable to include a possibility of exacerbated vasculitis in differential diagnosis of breast tumor in a patient with anti-neutrophil cytoplasmic antibodies positive granulomatosis.
Yet another conclusion from our case is related to the inadequacy of remission-inducing treatment of glomerular disease in systemic vasculitis for prevention of disease spreading and involvement of other organs.

\section{Declaration of conflicting interests}

The authors declared no conflicts of interest with respect to the authorship and/or publication of this article.

\section{Funding}

The authors received no financial support for the research and/or authorship of this article.

\section{REFERENCES}

1. Lie JT. Wegener's granulomatosis: histological documentation of common and uncommon manifestations in 216 patients. Vasa 1997;26:26170.

2. Barczynska T, Dankiewicz-Fares I, BilinskaReszkowska H, Zalewska J, Jeka S. Atypical location of Wegener's granulomatosis with breast involvement: case report. Ann Acad Med Stetin 2011;57:70-6.

3. Neralic-Meniga I, Ivanovi-Herceg Z, Mazuranic I, Puljic I, Zekan M, Gorecan M, et al. Wegener's granulomatosis of the breast. Wien Klin Wochenschr 2006;118:120-3.

4. Allende DS, Booth $\mathrm{CN}$. Wegener's granulomatosis of the breast: a rare entity with daily clinical relevance. Ann Diagn Pathol 2009;13:351-7.

5. Naz SM, Fairburn K. Pseudotumor of the breast: an unusual presentation of Wegener's granulomatosis. Breast J 2005;11:295-6.

6. Comas AG, Diana CA, Crespo CC, Cebollada MM, Liñán MA, Vila JV. Wegener's granulomatosis presented as recurrent breast abscess. Breast $\mathrm{J}$ 2010;16:82-4.

7. Altintoprak F, Kivilcim T, Ozkan OV. Aetiology of idiopathic granulomatous mastitis. World J Clin Cases 2014;2:852-8.

8. Fazzio RT, Shah SS, Sandhu NP, Glazebrook KN. Idiopathic granulomatous mastitis: imaging update and review. Insights Imaging 2016;7:531-9. 